\title{
Controlling the Growth of Palladium Aerogels with High- Performance toward Bioelectrocatalytic Oxidation of Glucose
}

\author{
Dan Wen ${ }^{\dagger}$, Anne-Kristin Herrmann ${ }^{\dagger}$, Lars Borchardt ${ }^{\ddagger}$, Frank Simon ${ }^{\S}$, Wei Liu ${ }^{\dagger}$, Stefan Kaskel ${ }^{\ddagger}$, and \\ Alexander Eychmüller*† \\ ${ }^{\dagger}$ Physical Chemistry, TU Dresden, Bergstrasse 66b, 01062 Dresden, Germany \\ ‡Inorganic Chemistry, TU Dresden, Bergstrasse 66, 01062 Dresden, Germany \\ ${ }^{\S}$ Leibniz Institute of Polymer Research Dresden, Hohe Strasse 6, 01069 Dresden, Germany
}

\section{Supporting Information Placeholder}

\begin{abstract}
We report controllable synthesis of Pd aerogels with high surface area and porosity by destabilizing colloidal solutions of Pd nanoparticles with variable concentrations of calcium ions. Enzyme electrodes based on Pd aerogels coimmobilized with glucose oxidase show high activity toward glucose oxidation and are promising materials for applications in bioelectronics.
\end{abstract}

The interest in metal nanomaterials has sparked a sustained research effort to develop synthetic methods and potential applications because of their novel electronic, catalytic, and optical properties. ${ }^{1}$ Metal aerogels, as a new kind of nanostructured materials, are highly porous monoliths with fine superstructures, which provide an opportunity to bridge the nanoscale world with that of materials of macro dimensions. Not only can they retain the inherent characteristics of aerogels, including high surface area, open interconnected porosity in the meso and macropore size range, and nanoscale particle sizes, but they also possess the unique properties of metal nanoparticles. ${ }^{2}$ Considering that metal nanoparticles (NPs) own excellent catalytic and conductive properties, aerogels from metal NPs may also find exciting applications in sensing, photovoltaics, and catalysis. Therefore, considerable progress is being made in the preparation of metal aerogels. For example, Leventis et al. have developed non-noble metal aerogels by a carbothermal method. ${ }^{3}$ Our group has reported on both a series of pure noble metal aerogels ${ }^{4}$ and metalsemiconductor aerogels ${ }^{5}$ prepared from solutions of colloidal NPs either via a spontaneous gelation method, or via a controllable destabilization approach. However, the development of synthetic methodology to control the morphology and porosity of such metal aerogels imposes important challenges. Furthermore, while this emerging multidisciplinary field attracts more attention, applications of colloidally derived metallic gels and aerogels are at its infancy.

In analogy to carbon aerogels, ${ }^{6}$ metal aerogels are expected to provide a matrix with high electrical conductivity and high surface area for electrochemical applications; however, unlike carbon aerogels, ${ }^{7}$ metal aerogels may also provide inherent catalytic activity and generally fast (reversible) e-transfer kinetics. ${ }^{8}$ In that respect, enzyme-loaded metallic aerogels in combination with their meso/macroporous structure can facilitate electron and mass transfer processes, which are both important for bioelectronic applications, for example in electrochemical biosensors and biofuel cells. ${ }^{9}$ To induce the assembly of Pd NPs for the gel formation and subsequent drying with supercritical $\mathrm{CO}_{2}$, we have developed a facile method with calcium ions as the destabilizing agent to prepare Pd aerogels. Interestingly, the growth of the Pd aerogels could be simply controlled by the addition of different concentrations of $\mathrm{Ca}^{2+}$. Using this novel approach, we produced Pd aerogels with different porosities and surface areas, which exhibited high activities towards the bioelectrooxidation of glucose when co-immobilized with glucose oxidase. The procedure of the Pd aerogel preparation (A) and a possible schematic representation of the $\mathrm{Ca}^{2+}$-induced assembly of citrate coated Pd NPs (B) are shown in Scheme 1 together with a photograph of the evolving aerogels induced by $0.1 \mathrm{mM} \mathrm{Ca}^{2+}(\mathrm{C})$.

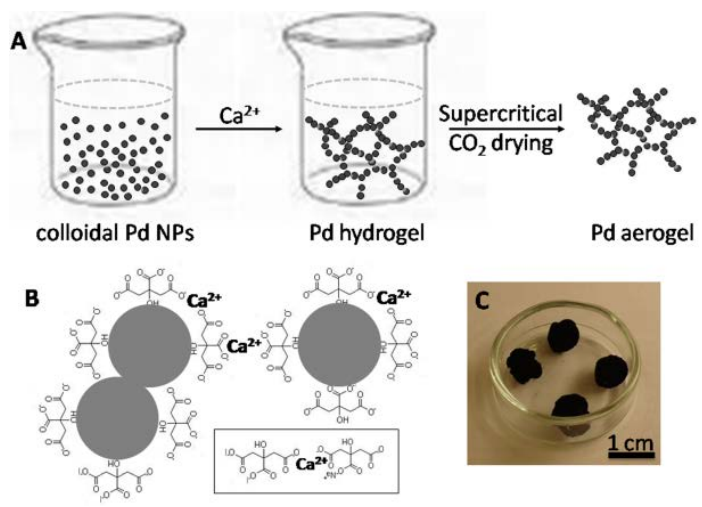

Scheme 1. Procedure of the Pd aerogel preparation (A), possible schematic representation for the $\mathrm{Ca}^{2+}$-induced assembly of citrate coated Pd NPs (B), and a photograph of the as-prepared Pd aerogels (C).

The citrate-stabilized Pd NPs as building blocks were synthesized by the reduction of $\mathrm{H}_{2} \mathrm{PdCl}_{4}$ with sodium borohydride in boiling water. Both the spectrophotometric and electron microscopic examinations confirmed the successful preparation of Pd NPs, which have an average diameter of $3 \mathrm{~nm}$ and a rather narrow 
size distribution (Figure S1, Supporting Information, SI). Aqueous colloidal solutions of metal NP decorated with citrate are normally very stable in the dilute as-prepared state. To induce gelation of those Pd colloids, efficient destabilization was initiated by concentrating the sols by a factor of 50 using ultracentrifugation (see SI). It is well-established that citrate is an important ion binder, which, owing to its high affinity for $\mathrm{Ca}^{2+}$, could neutralize the surface charge of citrate-coated metal NPs through specific interactions with the carboxylate groups causing destabilization of the NP system. ${ }^{10}$ Here we considered the possibility that $\mathrm{Ca}^{2+}$ induce the Pd NPs to assemble to form a hydrogel by the addition of $\mathrm{CaCl}_{2}$ solution to the concentrated colloids. Prior to the addition of the $\mathrm{Ca}^{2+}$, the NP solution for each sample was, as expected, homogeneous black. From Figure 1A and C, the introduction of the destabilizer significantly accelerated the gelation of the Pd hydrogels and fluffy black solids settled out of the solution within several minutes, days or weeks. Furthermore, all of the hydrogels were prepared with the same amount of concentrated Pd NPs. Different concentrations of $\mathrm{Ca}^{2+}$ had a dramatic effect on the volume (porosity) of the hydrogel samples. These results indicated that the growth of the Pd hydrogels was simply controlled by tuning the concentration of $\mathrm{Ca}^{2+}$. Notice that neither potassium nor chloride ions worked on the system for the gelation until above 2 months (sample 9), underlining the important role of $\mathrm{Ca}^{2+}$ during the gel formation process. Additionally, without the addition of $\mathrm{Ca}^{2+}$, the formation of a hydrogel was also observed after about 2 months while storing the Pd NP solutions in the dark (Sample 1). Figure 1B is a photograph of three typical Pd hydrogels transferred into acetone. These gelations were induced by different $\mathrm{Ca}^{2+}$ concentrations at $0.01,0.1$ and $1 \mathrm{mM}$, respectively.

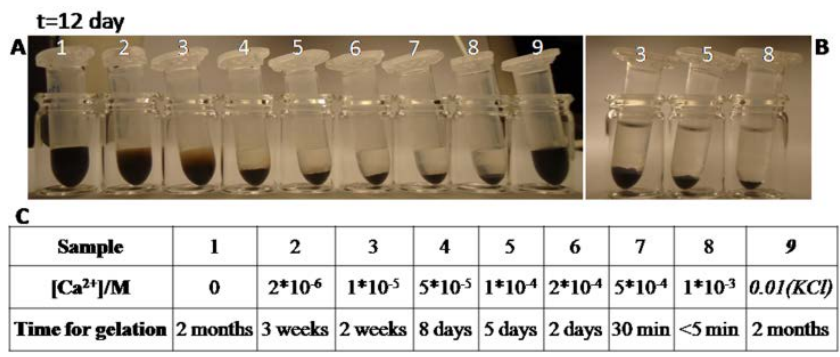

Figure 1. Photographs of the Pd NPs sols with various concentrations of $\mathrm{Ca}^{2+}$ (Sample 1-8, from 0 to $1 * 10^{-3} \mathrm{M}$ ), Time=12 days (A) and three typical Pd hydrogels transferred into acetone (B); summary of gel formation data (C).

Acetone-exchanged wet gels were dried with $\mathrm{CO}_{2}$ to aerogels. ${ }^{11}$ It was observed that varied morphologies of the aerogels were obtained depending on the amount of $\mathrm{Ca}^{2+}$ used as destabilizer (see Figure 2 and Figure S2, SI). Figure 2 shows scanning electron microscopy (SEM) images of three kinds of aerogels manufactured from Pd NPs with the use of 0.01 (Sample 3), 0.1 (Sample 5) and 1 (Sample 8) $\mathrm{mM} \mathrm{Ca}^{2+}$ (denoted as Pd A1, A2 and A3, respectively). The evolving structures of the Pd A1 and A2 are highly porous and composed of interconnected networks of ultrathin wire-like structures with many bifurcations and thicknesses of a few nanometers and pores larger than $50 \mathrm{~nm}$. By comparison, Pd aerogels made with higher $\mathrm{Ca}^{2+}$ concentrations (Pd A3) are much denser with smaller pore size in the range of mesopores. Photographs of four pieces of black Pd A2 with diameters of around 5-6 mm are depicted in scheme 1C. Based on volume and weight of the samples, the average densities of the materials were $0.025,0.029$ and $0.059 \mathrm{~g} \mathrm{~cm}^{-3}$, corresponding to approximately $1 / 480,1 / 414$ and $1 / 203$ of the bulk density of Pd. These values are in the typical range of aerogel densities $\left(0.004-0.500 \mathrm{gcm}^{-3}\right)$ and underlining high porosities. ${ }^{12}$

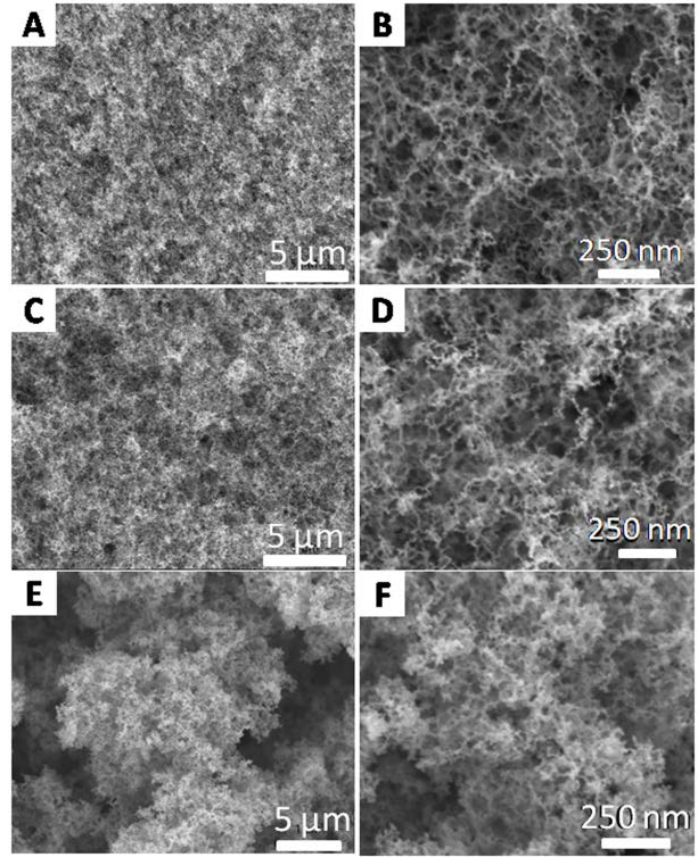

Figure 2. SEM images of aerogels: Pd A1 (A, B), Pd A2 (C, D), and Pd A3 (E, F), respectively.

The specific surface area and porosity of the resulting aerogels were further evaluated by nitrogen physisorption measurements carried out with the Pd A2 and A3 since the SEM imaging showed similar morphologies of the $\mathrm{Pd} \mathrm{A} 1$ and $\mathrm{A} 2$ as discussed above. As shown in Figure S3A, type II isotherms are observed which is characteristic for macropores containing materials. The specific surface areas of the Pd A2 and A3 were determined to be 40 and $108 \mathrm{~m}^{2} \mathrm{~g}^{-1}$, respectively, which are in the typical range reported for noble metal aerogels. ${ }^{4}$ A broad distribution of pores is in good accordance with the structural properties obtained from the SEM characterizations. In addition, pore volumes of 0.15 and $0.4 \mathrm{~cm}^{3} \mathrm{~g}^{-1}$ for pores smaller than $50 \mathrm{~nm}$ were estimated for Pd A2 and A3. In combination with the pore size distribution assessed from the desorption branch using the Barrett-JoynerHalenda (BJH) equation (Figure S3B, SI), it is suggested that Pd A3 contained more and smaller pores on the mesoscale $(2-50 \mathrm{~nm})$ than Pd A2.

TEM analysis was thus conducted to characterize the materials in detail to unravel the assembly state of the NPs with regard to $\mathrm{Ca}^{2+}$. For Pd A2, as seen from Figure $3 \mathrm{~B}$ and $\mathrm{D}$, long chains of $\mathrm{Pd}$ NPs exist with a number of branching points, resulting in a network-like organization of the linear chains into a superstructure. The aerogel has a porous network structure composed of ultrathin primary nanochains with relatively uniform diameters of about 3$10 \mathrm{~nm}$. Considering that the aerogel has typical dimensions on a similar size scale as the diameter of the original NPs, we conclude that the aerogel is formed directly from the original colloidal particles with some fusions of nanoparticles of different size. For the Pd A1 shown in Figure 3A, also some small independent NP assemblies are detected in this sample, while some regions of the Pd A3 display a more uncontrolled aggregated structure of variable size (Figure 3C).

All the results mentioned above show that $\mathrm{Ca}^{2+}$ in the Pd NPs sols determine the final porous properties of the Pd aerogels. It is reported that also the time for gelation could affect the pore structure in aerogels. ${ }^{13}$ Here a large amount of $\mathrm{Ca}^{2+}$ provides a better opportunity to interact with the capping agents of the NPs and accelerate the assembly process, and subsequently shorten the time for gelation (as summarized in Figure 1C). Palladiumsodium citrate sols are viewed as one of the most stable hydrosols 
of Pd. ${ }^{14}$ However, as the concentration step reduced the surface charge of the Pd particles, and the added $\mathrm{Ca}^{2+}$ interacted with the citrate ions on the surface of the Pd NPs, the surface charge was further decreased $(\xi$-potential Pd gel $=-32.7 \mathrm{mV}$ ) and made the sol system more unstable. Since the existence of calcium in the aerogel samples was neither detected through energy-dispersive X-ray spectroscopy nor XPS (Figure S4A, SI), and also not with the even more sensitive analytic method inductively coupled plasma optical emission spectroscopy, we couldn't simply assume that $\mathrm{Ca}^{2+}$ acts as an interparticle bridge to connect the neighboring Pd NPs via the interaction with citrate on the NP surfaces and subsequently induce the assembly. Another mechanism could be that by the action of $\mathrm{Ca}^{2+}$, the citrate is partly removed away from the surface of the NPs, leaving them with a relatively "clean" surface and by this being more vulnerable for gelation. Since the exact reasons are not yet known, we are still studying the formation mechanism of the cation-induced Pd hydrogels.

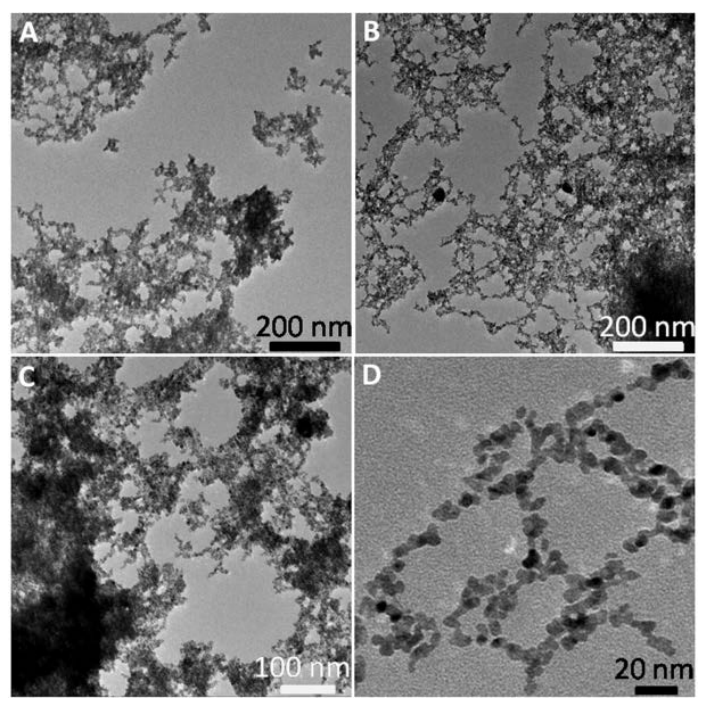

Figure 3. TEM images of aerogels (Pd A1-3) from Pd NPs destabilized from solution by the addition of $\mathrm{Ca}^{2+}$. The concentration of $\mathrm{Ca}^{2+}$ is $0.01 \mathrm{mM}(\mathrm{A}), 0.1 \mathrm{mM}(\mathrm{B}, \mathrm{D})$, and $1 \mathrm{mM}(\mathrm{C})$, respectively.

Further characterization of the as-prepared aerogels (Pd A1-A3) was carried out with $\mathrm{x}$-ray powder diffraction. The spectra show diffraction peaks assigned to the $\{111\},\{200\},\{220\}\{311\}$, and $\{220\}$ planes of the face-centered-cubic (fcc) polycrystalline structure (Figure S5, SI). The binding energies obtained from XPS of 335.35 and $340.65 \mathrm{eV}$ correspond to $\mathrm{Pd}\left(3 \mathrm{~d}_{5 / 2}\right)$ and $\mathrm{Pd}\left(3 \mathrm{~d}_{3 / 2}\right)$, respectively, which confirmed that mainly metallic $\mathrm{Pd}$ was obtained in the aerogel samples (Figure S4B, SI).

With their high porosity, large surface area, and excellent catalytic activity, new nanostructured metallic aerogels can be expected to be promising electrode in bioelectrocatalysis. For a long time, the bioelectrocatalytic oxidation of glucose has been the focus of many investigations, because of the great importance of sugar sensing in human blood, and their potential use for biofuel cell applications. ${ }^{15}$ In the present work, glucose oxidase (GOD) was taken as an example to demonstrate the bioelectrocatalytic application of Pd aerogels as electrode enhancing materials by the combination of Pd aerogels (Pd A1-3), GOD and Nafion, using ferrocenecarboxylic acid $(\mathrm{Fc})$ as electron mediator.

Cyclic voltammograms (CVs) on GOD-Nafion, Pd NPs-GODNafion, and Pd A (1-3)-GOD-Nafion modified glassy carbon (GC) electrodes were recorded at scan rates in the range from 5 to $200 \mathrm{mV} \mathrm{s}^{-1}$, in $0.1 \mathrm{M}$ phosphate buffer solution (PBS, pH 7.4) (Figure S6, SI). In the potential region from 0 to $0.6 \mathrm{~V}$, all modified electrodes displayed symmetrical CV curves with nearly equal reduction and oxidation peak heights upon the addition of
$0.2 \mathrm{mM}$ Fc. The peak-to-peak potential separation $\left(\Delta E_{p}\right)$ was calculated to be $75,71,63,56$ and $67 \mathrm{mV}$ at $20 \mathrm{mV} \mathrm{s}^{-1}$, respectively, which indicated that the mediator underwent a quasireversible redox process on these enzyme electrodes. The overall smaller values of $\Delta E_{p}$ observed from the Pd aerogel-based electrodes implied much faster electron-transfer kinetics of the mediator at the Pd aerogel/GOD film surface. ${ }^{16}$ In proportion to the scan rate, both the oxidation and reduction peak currents of the modified electrodes increased linearly with the square root of the scan rate, suggesting that the reaction was controlled by a semi-infinite linear diffusion. The larger values of the slopes for the linear regression equations obtained at the Pd A-GOD-Nafion/GC electrodes revealed that the unique electron structure endows of the Pd aerogel-enzyme films with fast electron and mass transfer (Table S1, SI). ${ }^{17}$
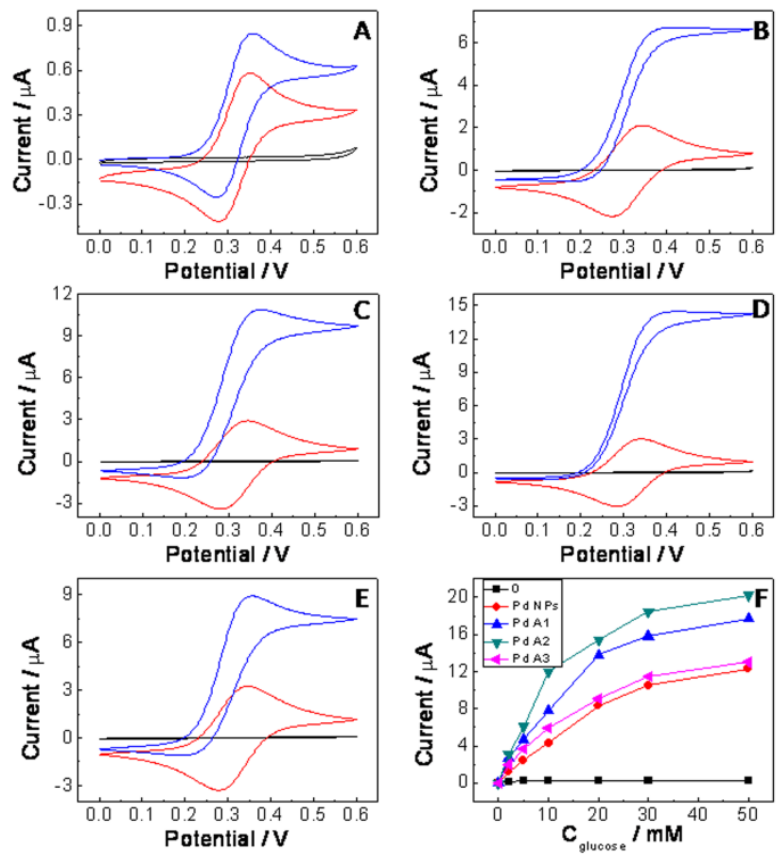

Figure 4. CVs of GOD-Nafion/GC(A), Pd NPs-GOD-Nafion/GC (B), Pd A (1-3)-GOD-Nafion/GC (C-E) Electrodes in 0.1 M PBS (pH 7.4) (black line), with $0.2 \mathrm{mM} \mathrm{Fc}$ (red line), and with $0.2 \mathrm{mM}$ Fc+10 mM glucose (blue line). The scan rate is $20 \mathrm{mV} \mathrm{s}^{-1}$. (F) Calibration curve derived from different glucose concentrations (2-50 $\mathrm{mM})$ for the above-mentioned modified electrodes.

In the presence of $10 \mathrm{mM}$ glucose, the anodic current increased drastically, meanwhile, the cathodic current decreased, which meant the bioelectrocatalytic oxidation of glucose, as shown in Figure 4 . These five enzyme electrodes showed catalytic currents of $0.22 \pm 0.01,4.27 \pm 0.14,7.79 \pm 0.23,11.96 \pm 0.34$, and $5.92 \pm 0.17$ $\mu \mathrm{A} \quad(\mathrm{n}=5)$, respectively. Evidently, the Pd A-GOD-Nafion/GC exhibited much higher bioelectrocatalytic activities compared with GOD-Nafion/GC and Pd NPs-GOD-Nafion/GC electrodes, which implied a dramatic increase in the bioelectrocatalytic function of the Pd aerogel modified electrodes. We also investigated the bioelectrocatalyzed response of different concentrations of glucose by these electrodes. As the concentration of glucose was increased, also the anodic currents increased. The resulting calibration curves are shown as Figure 4F. The current sensitivity of the Pd A2-based enzyme electrode toward glucose in the range from 2 to $20 \mathrm{mM}$ was estimated to be $1.11 \mu \mathrm{A} \mathrm{mM}{ }^{-1}$, which is 125 and 3 times higher than those of GC and Pd NPs as enzyme supports, respectively, and also much superior to those observed for mediated GOD in other porous matrices. ${ }^{18}$ In addition, the enzyme electrodes based on Pd aerogel revealed 12 hours stability under 
continuous operation and $~ 95 \%$ of catalytic current upon storage at $4{ }^{\circ} \mathrm{C}$ for two weeks.

The electrochemical results indicated that the modification with Pd aerogel substantially improved the bioelectrocatalytic performance of the enzyme electrode, which may be ascribed to the following effects: (1) the introduction of noble metal aerogel increased the conductance within the enzyme film and improved the electrical communication between the electrode and the ferrocene units that mediate the bioelectrocatalytic oxidation; (2) the porous structures of the Pd aerogels not only allow fast transport of the substrate as well as the mediator through the electrolyte/electrode interface due to short diffusion length but also ensure contact with a larger surface due to the high surface area, and by this facilitating the electrochemical reactions. ${ }^{19}$ In addition, it is noticed that even though the Pd A3 has much higher surface area than Pd A2, the best bioelectrocatalytic behavior was obtained for the Pd A1 and A2-based enzyme electrodes. This outstanding performance was probably due to the unique inherent porous structure of Pd A1 and A2 as shown in the SEM images and $\mathrm{N}_{2}$ adsorption analysis, where the interconnected porous structure with the larger accessible inner surface and higher regularity could offer a higher enzyme loading and more benefit for the reactant diffusion. ${ }^{20}$

In summary, we demonstrated the facile, reproducible and controlled formation of highly porous Pd aerogels via a $\mathrm{Ca}^{2+}$ induced assembly with subsequent supercritical drying. The aerogels were composed of three-dimensional network structures and displayed very high surface area and large porosity. Furthermore, for the first time, the Pd aerogels were applied in bioelectrocatalysis, and the electrochemical results showed that the Pd aerogel-based enzyme electrodes exhibit high activities towards the ferrocenemediated oxidation of glucose, which could promise potential applications of the high-performance glucose biosensors and glucose $/ \mathrm{O}_{2}$ biofuel cells.

\section{ASSOCIATED CONTENT}

\section{Supporting Information}

Experimental section, Pd NPs synthesis and characterization, SEM images, $\mathrm{N}_{2}$ adsorption/desorption isotherms, XPS and XRD data of Pd aerogels induced by different concentration of $\mathrm{Ca}^{2+}$, and enzyme electrodes preparation and electrochemical characterization. This material is available free of charge via the Internet at http://pubs.acs.org.

\section{AUTHOR INFORMATION}

\section{Corresponding Author}

alexander.eychmueller@chemie.tu-dresden.de

\section{Notes}

The authors declare no competing financial interests.

\section{ACKNOWLEDGMENT}

D. Wen acknowledges the support from the Alexander von Humboldt Foundation. This work is also supported by DFG GRK1401 and DFG project EY16/10-2. We thank Susanne Goldberg for the SEM measurements and Nikolai Gaponik, Stephen Hickey, Jan Poppe, and Paul Mundra for their discussions and help.

\section{REFERENCES}

(1) a) Porter, N. S.; Wu, H.; Quan, Z. W.; Fang, J. Y. Acc. Chem. Res. 2013, 46, 1867-1877; b) Guo, S. J.; Sun, S. H. J. Am. Chem. Soc. 2012 134, 2492-2495; c) Snyder, J.; Asanithi, P.; Dalton, A. B.; Erlebacher, J. Adv. Mater. 2008, 20, 4883-4886.
(2) a) Gesser, H. D.; Goswami, P. C. Chem. Rev. 1989, 89, 765-788; b) Gaponik, N.; Herrmann, A. -K.; Eychmüller, A. J. Phys. Chem. Lett. 2012, 3, 8-17.

(3) a) Leventis, N.; Chandrasekaran, N.; Sadekar, A. G.; SotiriouLeventis, C.; Lu, H. J. Am. Chem. Soc. 2009, 131, 4576-4577; b) Leventis, N.; Chandrasekaran, N.; Sadekar, A. G.; Mulik, S.; SotiriouLeventis, C. J. Mater. Chem. 2010, 20, 7456-7471; c) Leventis, N.; Chandrasekaran, N.; Sotiriou-Leventis, C.; Mumtaz, A. J. Mater. Chem. 2009, 19, 63-65.

(4) a) Bigall, N. C.; Herrmann, A. -K.; Vogel, M.; Rose, M.; Simon, P.; Carrillo-Cabrera, W.; Dorfs, D.; Kaskel, S.; Gaponik, N.; Eychmüller, A. Angew. Chem. Int. Ed., 2009, 48, 9731-9734; b) Liu, W.; Herrmann, A. K.; Geiger, D.; Borchardt, L.; Simon, F.; Kaskel, S.; Gaponik, N.; Eychmüller, A. Angew. Chem. Int. Ed. 2012, 51, 5743-5747; c) Liu, W.; Rodriguez, P.; Borchardt, L.; Foelske, A.; Yuan, J. P.; Herrmann, A. -K.; Geiger, D.; Zheng, Z. K.; Kaskel, S.; Gaponik, N.; Kötz, R.; Schmidt, T. J.; Eychmüller, A. Angew. Chem. Int. Ed. 2013, 52, 9849-9852.

(5) a) Gill, S. K.; Hope-Weeks, L. J. Chem. Commun. 2009, 4384 4386; b) Lesnyak, V.; Wolf, A.; Dubavik, A.; Borchardt, L.; Voitekhovich, S. V.; Gaponik, N.; Kaskel, S.; Eychmüller, A. J. Am. Chem. Soc. 2011, 133, 13413-13420; c) Hendel, T.; Lesnyak, V.; Kühn, L.; Herrmann, A. -K.; Bigall, N. C.; Borchardt, L.; Kaskel, S.; Gaponik, N.; Eychmüller, A. Adv. Funct. Mater. 2013, 23, 1903-1911.

(6) Al-Muhtaseb, S A.; Ritter, J. A. Adv. Mater. 2003, 15, 101-114.

(7) Leventis, N.; Mulik, S.; Sotiriou-Leventis, C. Chem. Mater. 2008, 20, 6985-6997.

(8) a) Minteer, S. D.; Liaw, B. Y.; Cooney, M. J. Curr. Opin. Biotechnol. 2007, 18, 228-234; b) Kamitaka, Y.; Tsujimura, S.; Setoyama, N.; Kajino,T.; Kano, K. Phys. Chem. Chem. Phys. 2007, 9, 1793-1781.

(9) a) Heller, A.; Acc. Chem. Res. 1992, 23, 209-216; b) Willner, I. Science 2002, 298, 2407-2408; c) Gao, F.; Viry, L.; Maugey, M.; Poulin, P.; Mano, N. Nat. Commun. 2010, 1:2; d) Zhou, M.; Dong, S. J. Acc. Chem. Res. 2011, 44, 1232-1243.

(10) a) López-Macipe, A.; Gómez-Morales, J.; Rodríguez-Clemente, R. Adv. Mater. 1998, 10, 49-53; b) Huynh, K. A.; Chen, K. L. Environ. Sci. Technol. 2011, 45, 5564-5571.

(11) Mohanan, J. L.; Arachchige, I. U.; Brock, S. L. Science 2005, 307, 397-400.

(12) Hüsing, N.; Schubert, U. Angew. Chem. Int. Ed. 1998, 37, 22-45.

(13) Job, N.; Panariello, R.; Crine, M.; Pirard, J. P.; Leonard, A. Colloids and Surfaces A 2007, 293, 224-228.

(14) Turkevich, J.; Kim, G. Science 1970, 169, 873-879.

(15) a) Wang, J.; Chem. Rev. 2008, 108, 814-825; b) Heller, A.; Feldman, B. Chem. Rev. 2008, 108, 2482-2505; c) Willner, I.; Yan, Y. M.; Willner, B.; Tel-Vered, R. Fuel Cells 2009, 9, 7-24.

(16) a) Gong, K. P.; Chakrabarti, S.; Dai, L. M. Angew. Chem. Int. Ed. 2008, 47, 5446-5450; b) Liu, F.; Seo, T. S. Adv. Funct. Mater. 2010, 20, 1930-1936.

(17) Tang, L. H.; Wang, Y.; Li, Y. M.; Feng, H. B.; Lu, J.; Li, J. H. Adv. Funct. Mater. 2009, 19, 2782-2789.

(18) a) Liu, Y.; Wang, M. K.; Zhao, F.; Xu, Z. A.; Dong, S. J. Biosens. Bioelectron. 2005, 21, 984-988; b) Kandimalla, V. B.; Tripathi, V. S.; Ju, H. X. Biomaterials 2006, 27, 1167-1174; c) Dai, Z. H.; Ni, J.; Huang, X. H.; Lu, G. F.; Bao, J. C. Bioelectrochemistry 2007, 70, 250-256; d) Bao, S. J.; Li, C. M.; Zang, J. F.; Cui, X. Q.; Qiao, Y.; Guo, J. Adv. Funct. Mater. 2008, 18, 591-599; e) Deng, C. Y.; Peng, Y.; Su, L.; Liu, Y. N.; Zhou, F. M. Anal. Chim. Acta. 2012, 719, 52-56; f) Cui, M.; Xu, B.; Hu, C. G.; Shao, H. B.; Qu, L. T. Electrochim. Acta 2013, 98, 48-53.

(19) a) Yan, Y. M.; Tel-Vered, R.; Yehezkeli, O.; Cheglakov, Z.; Willner, I. Adv. Mater. 2008, 20, 2365-2370; b) Newman, J.; Tiedemann, W. AIChE Journal 1975, 21, 25-41.

(20) a) Mezedur, M. M.; Kaviany, M. AIChE Journal 2002, 48, 15-24; b) Tsujimura, S.; Nishina, A.; Hamano, Y.; Kano, K.; Shiraishi, S. Electrochem. Comm. 2010, 12, 446-449. 
Table of Contents (TOC)

Controlling the Growth of Palladium Aerogels with High-Performance toward Bioelectrocatalytic Oxidation of Glucose

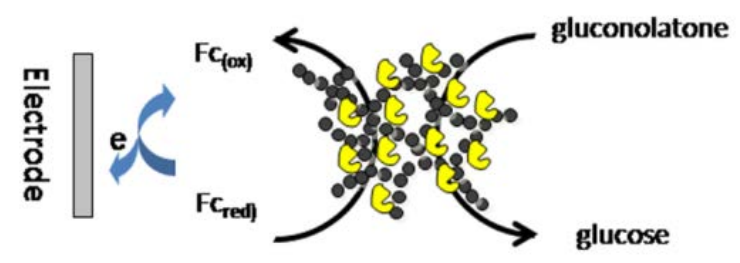

